\title{
DISCORDANCE BETWEEN ONE-HOUR AND ANNUAL LIMITS OF THE WORLD HEALTH ORGANIZATION AIR QUALITY GUIDELINE (WHOAQG) FOR NO2
}

\author{
Hak-Kan Lai, School of Public Health, The University of Hong Kong, Hong Kong SAR, China \\ Anthony J Hedley, School of Public Health, The University of Hong Kong, Hong Kong SAR, China \\ Chit-Ming Wong, School of Public Health, The University of Hong Kong, Hong Kong SAR, China
}

Background and Aims: It is important to ensure the short-term and annual AQG are valid and robust to provide support to setting standards which, if enforced, will reliably ensure that exposure reduction targets are met effectively for health protection. Methods: We developed a lognormal distribution model to examine the relationship between short-term and annual AQG for $\mathrm{NO}_{2}$ using data in 2010 in Hong Kong and London. This model, which takes into account the allowable exceedances of AQG, was robust after extreme values (4 times the geometric standard deviation above the geometric mean) were excluded [2].

Results: The WHOAQG of $40 \bullet \mathrm{g} / \mathrm{m}^{3}$ cannot be achieved through compliance with short-term limit of $200 \cdot \mathrm{g} / \mathrm{m}^{3}$. The predicted 1 hr AQG is sensitive to the standard deviation of the ambient mass concentration, and estimated to be $140 \cdot \mathrm{g} / \mathrm{m}^{3}$ and $128 \cdot \mathrm{g} / \mathrm{m}^{3}$ in Hong Kong and London respectively. In the model validation using WHO 24-hr AQG for $\mathrm{PM}_{10} / \mathrm{PM}_{2.5}$, we obtained reliable prediction of annual AQG for $\mathrm{PM}_{10}\left(21.5 \cdot \mathrm{g} / \mathrm{m}^{3}\right)$ and $\mathrm{PM}_{2.5}\left(10.3 \cdot \mathrm{g} / \mathrm{m}^{3}\right)$ in Hong Kong.

Conclusions: The large difference between WHO 1-hr limit $\left(200 \cdot \mathrm{g} / \mathrm{m}^{3}\right)$ and the predicted limit indicates statistical discordance between the short-term and annual $\mathrm{NO}_{2}$ limits in the current WHOAQG, in contrast to other criteria pollutants. Based on public health principles, the short- and long-term epidemiologic evidence and need to ensure validity of health impact assessments, the 1-hr AQG should be between 128 and $140 \cdot \mathrm{g} / \mathrm{m}^{3}$ given the standard deviations observed in typical traffic dense environments. Factors affecting the standard deviation may include number of monitors, sampling locations, pollution sources, and meteorological factors. Data from other cities is needed.

\section{References:}

[1] World Health Organization (WHO). Air Quality Guidelines Global Update 2005: particulate matter, ozone, nitrogen dioxide and sulphur dioxide. Copenhagen: WHO Regional Office for Europe 2006..

[2] Lai HK, Wong CM, McGhee SM, Hedley AJ. Assessment of the health impacts and economic burden arising from proposed new Air Quality Objectives in a high pollution environment. Open Epidemiol J. 2011;4:106-122. 